ISSN 1112-9867

Available online at

http://www.jfas.info

\title{
MULTI-ELEMENTAL ANALYSIS OF COLONIAL AND POST-COLONIAL NIGERIAN COINS BY PROTON INDUCED X-RAY EMISSION (PIXE) SPECTROMETRY
}

\author{
G. C. Ezeh* and E. I. Obiajunwa \\ Centre for Energy Research and Development, Obafemi Awolowo University, Ile-Ife, Nigeria
}

Received: 12 September 2016 / Accepted: 27 December 2016 / Published online: 01 January 2017

\begin{abstract}
The investigation of old and new coins from different countries in the world has generated a growing interest among numismatic and archaeological researchers. The challenge is to explain the large diversification of these coins, to determine the differences in composition, weight and physical aspects. A non-destructive physical method of ion beam analysis; PIXE was employed to investigate elemental properties of colonial and post-colonial Nigerian coins. The weights of the coins varied between 1.89 and $11.46 \mathrm{~g}$ while their thicknesses ranged from 0.10 to $0.40 \mathrm{~mm}$. The elements; $\mathrm{Al}, \mathrm{Si}, \mathrm{Mn}, \mathrm{Fe}$ and $\mathrm{Zn}$ were detected along with the major components of $\mathrm{Ni}$ and $\mathrm{Cu}$. The elements displayed both positive and negative correlations. The study could aid in solving some scientifically questions of conservators and tourists on "what" material is it especially now that coins have long been demonetized in Nigeria.
\end{abstract}

Keywords: archaeology, coins, composition, numismatic, PIXE.

Author Correspondence, e-mail: goddyich@yahoo.com

doi: http://dx.doi.org/10.4314/jfas.v9i1.28

\section{INTRODUCTION}

Elemental composition studies of ancient objects (such as ancient glasses, coins, ceramics, metal alloys, ornaments, wooden wares and so on) are necessary in archaeology as 
information regarding technology, provenance and other historical facts could be revealed. Again, the elemental analyses of artefacts such as ancient coins could provide valuable information regarding metallurgy and economy at the time of minting. The problem arises from the necessity to explain large diversifications of these coins as well as the differences in compositions, weights and physical aspects. Coins usually have a roughly homogenous core and mostly thin surface layer with different compositions and varying thickness. The layers can be enriched, oxidized, corroded or soiled during usage or storage.

Several spectroscopic techniques such as atomic absorption spectroscopy (AAS), x-ray fluorescence with an energy dispersive detection system (EDXRF) spectroscopy and transmission electron microscopy have been used in the past to study the chemical compositions of Indian ancient coins (Hajivaliei et al., 1999). Proton Induced X-ray Emission (PIXE) experiment, an accelerator-based ion beam analysis (IBA) technique has been applied to the studies of archaeological objects for many years (Cohen et al., 2004). PIXE is well suited for such studies because of its unique advantages; it is non-destructive, multi-elemental, fast, low minimum detection limits (MDLs) for a very broad range of elements in the Periodic Table and can quantitatively detect picograms of materials in micrograms of samples. It is comparatively universal, i.e. applicable to many materials and objects of any dimension. Therefore, large number of objects from archaeological excavations or museum collections could be studied.

A preliminary survey to investigate the chemical compositions of Hindu Shahis Dynasty of Kabul coins have been reported (Hajivaliei et al., 1999). In Nigeria, little or no analytical work has been reported on ancient pre or post-colonial coins, thus information on elemental compositions is grossly dearth. Hence, in this work PIXE was applied for the elemental characterization of colonial and pre-colonial Nigerian coins.

\subsection{Brief history of Nigerian currency}

The West African Currency Board was responsible for issuing currency notes and coins in Nigeria from 1912 to 1959. Prior to the establishment of West African Currency Board, Nigeria had used various forms of money including cowries and manilas. On 1st July, 1959 the Central Bank of Nigeria issued Nigerian currency notes and coins while the West African Currency Board notes and coins were withdrawn. It was not until $1^{\text {st }}$ July, 1962 that legal tender status 
was changed to reflect the country's new independent status. Nigerian government changed to decimal currency in 1st January, 1973 with major currency unit called Naira which was equivalent to ten shillings while the minor unit was kobo; 100 of which would make one Naira. In 1973, coins were introduced in denominations of $1 / 2,1,5,10$ and 25 kobo while in 1991, 50 kobo, 1 and 2 naira coins came on board. However, it is sad to note that due to bad economic policies, Nigerian coins are now only visible in the archives as they have long been demonetized.

\section{RESULTS AND DISCUSSION}

\subsection{Physical characteristics of the samples}

Table 1 displayed the physical characteristics (weight, thickness and diameter) of the coins. The weights ranged from 1.89 to $11.46 \mathrm{~g}$ with average mean weights of $4.71 \mathrm{~g}$. Again, the thickness and diameter were in the range of 0.10 to $0.40 \mathrm{~mm}$ and 17.70 to $27.60 \mathrm{~mm}$ respectively. The standard variance of the physical parameters showed no significant variation in the thickness $\left(S^{2}=0.01\right)$ while the weights $\left(S^{2}=8.52\right)$ and diameter $\left(S^{2}=10.12\right)$ varied significantly.

Table 1: Physical characteristics of the coins

\begin{tabular}{llll} 
Coins & Weight $(\mathrm{g})$ & Thickness $(\mathrm{mm})$ & Diameter $(\mathrm{mm})$ \\
\hline 1 & 7.48 & 0.20 & 26.00 \\
2 & 3.40 & 0.13 & 21.60 \\
3 & 5.65 & 0.14 & 25.00 \\
4 & 4.40 & 0.16 & 22.40 \\
5 & 2.67 & 0.12 & 20.00 \\
6 & 11.46 & 0.40 & 27.60 \\
7 & 2.94 & 0.13 & 19.00 \\
8 & 2.37 & 0.13 & 17.70 \\
9 & 1.89 & 0.10 & 20.30 \\
10 & 4.84 & 0.16 & 22.80 \\
Variance $\left(\mathrm{S}^{2}\right)$ & 8.52 & 0.01 & 10.12
\end{tabular}

\subsection{Calibration of PIXE set-up}

The results of the Certified Standard reference for six thin-film samples are presented in Table 2 alongside with their corresponding laboratory observed values and PIXE efficiency values. This was to validate the outcome of PIXE data as well as to determine its efficiency. The geometry of samples plays a decisive role in the quantitative PIXE experiment, therefore the 
ionized layers were within the flat surface so that self-absorption effects of the X-ray emission are negligible. The laboratory observed values of $\mathrm{Si}, \mathrm{K}, \mathrm{Ca}, \mathrm{Fe}, \mathrm{Ru}$ and $\mathrm{Pb}$ reference thin-films standards recorded at least $94 \%$ efficiency in each sample. Results were in agreement with the certified values, which indicate the reliability and reproducibility of PIXE facility employed for elemental analysis.

Table 2: PIXE set-up efficiency measurement with reference standard

Thin Film IAEA certified reference Observed experimental PIXE efficiency

\begin{tabular}{cccc} 
Labels & values $\left(\mu \mathrm{g} \mathrm{cm}^{-2}\right)$ & values $\left(\mu \mathrm{g} \mathrm{cm}^{-2}\right)$ & $(\%)$ \\
\hline $\mathrm{Si}$ & 43.1 & 41.7 & 96.8 \\
$\mathrm{~K}$ & 53.0 & 50.1 & 94.5 \\
$\mathrm{Ca}$ & 47.4 & 46.5 & 98.1 \\
$\mathrm{Fe}$ & 46.3 & 46.4 & 100.2 \\
$\mathrm{Ru}$ & 46.1 & 44.1 & 95.7 \\
$\mathrm{~Pb}$ & 52.8 & 50.9 & 96.4
\end{tabular}

\subsection{Elemental composition of the samples}

In general, the concentrations of $\mathrm{Al}, \mathrm{Si}, \mathrm{Mn}, \mathrm{Fe}, \mathrm{Zn}$ alongside the major elements $\mathrm{Ni}$ and $\mathrm{Cu}$ were detected (Table 3 ) in the coin samples. Measurement errors were typically of the order \pm 1 to $\pm 10 \%$ for most species due to fundamental parameters and efficiency calibrations. Fig. 1 displayed the spectrum of coin no 4.

The coins were mainly either of $\mathrm{Cu}$ or $\mathrm{Ni}$ unlike the ancient coins of India which were made up of $\mathrm{Cu}$ and $\mathrm{Ag}$ (Hajivaliei et al., 1999). The variations for $\mathrm{Cu}$ ranged from 33400 to 57900 $\mathrm{ng} \mathrm{cm}^{-2}$ while Ni is from 10 to $47900 \mathrm{ng} \mathrm{cm}^{-2}$. Samples labelled 2, 3, 4, 5, 7, 8 and 9 were in "Cu" group while 1, 6 and 10 belong to "Ni" group simply because the concentrations of $\mathrm{Cu}$ and $\mathrm{Ni}$ were more pronounced than other elements. The concentration of $\mathrm{Cu}\left(46800 \mathrm{ng} \mathrm{cm}^{-2}\right)$ in sample no. 2 is nearly ten times $\mathrm{Zn}$ concentration $\left(600 \mathrm{ng} \mathrm{cm}^{-2}\right)$ thus indicate that the bulk of the sample is $\mathrm{Cu}$ based. Similarly, sample 3 to 8 followed similar pattern. 


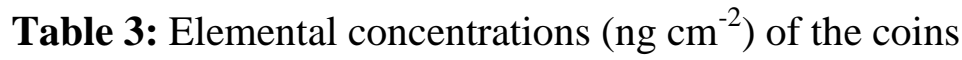

\begin{tabular}{|c|c|c|c|c|c|c|c|}
\hline Coins & $A l$ & $\mathrm{Si}$ & $M n$ & $\mathrm{Fe}$ & $N i$ & $\mathrm{Cu}$ & $Z n$ \\
\hline 1 & $0.63(0.04)$ & $1.42(0.08)$ & $33.92(1.73)$ & $62.35(2.46)$ & $47943.30(76.71)$ & nd & nd \\
\hline 2 & $0.75(0.04)$ & $3.04(0.11)$ & $0.78(0.70)$ & $15.53(1.71)$ & $\mathrm{Nd}$ & $46814.27(55.95)$ & $586.20(25.97)$ \\
\hline 3 & $0.55(0.04)$ & $1.32(0.07)$ & nd & $35.71(2.07)$ & $\mathrm{Nd}$ & $57909.14(110.03)$ & nd \\
\hline 4 & $1.29(0.06)$ & $6.61(0.18)$ & $1.87(0.81)$ & $384.00(4.65)$ & $9.49(3.81)$ & $51443.27(92.60)$ & $634.70(27.36)$ \\
\hline 5 & $0.72(0.08)$ & $2.56(0.13)$ & $44.52(1.87)$ & $35.32(2.53)$ & $9879.13(39.52)$ & $39746.62(103.34)$ & $259.20(14.02)$ \\
\hline 6 & $0.69(0.04)$ & $1.03(0.06)$ & nd & $1534.00(9.36)$ & $37515.13(67.53)$ & nd & nd \\
\hline 7 & $0.30(0.06)$ & $1.78(0.09)$ & $55.55(1.78)$ & $57.68(2.55)$ & $7495.39(38.22)$ & $33441.21(123.73)$ & $237.60(12.55)$ \\
\hline 8 & $0.29(0.07)$ & $2.65(0.11)$ & $12.71(1.17)$ & $34.24(2.17)$ & $8435.29(33.74)$ & $34101.41(78.43)$ & $241.90(12.82)$ \\
\hline 9 & $0.74(0.04)$ & $1.28(0.07)$ & nd & $9.22(1.70)$ & $562.80(8.78)$ & $45936.08(87.28)$ & 8981.11 (52.99) \\
\hline 10 & $0.64(0.07)$ & $1.82(0.10)$ & $42.36(1.69)$ & $27.90(2.29)$ & $11525.14(39.19)$ & $37641.57(82.81)$ & $368.60(13.68)$ \\
\hline
\end{tabular}

"nd" means not "detected"

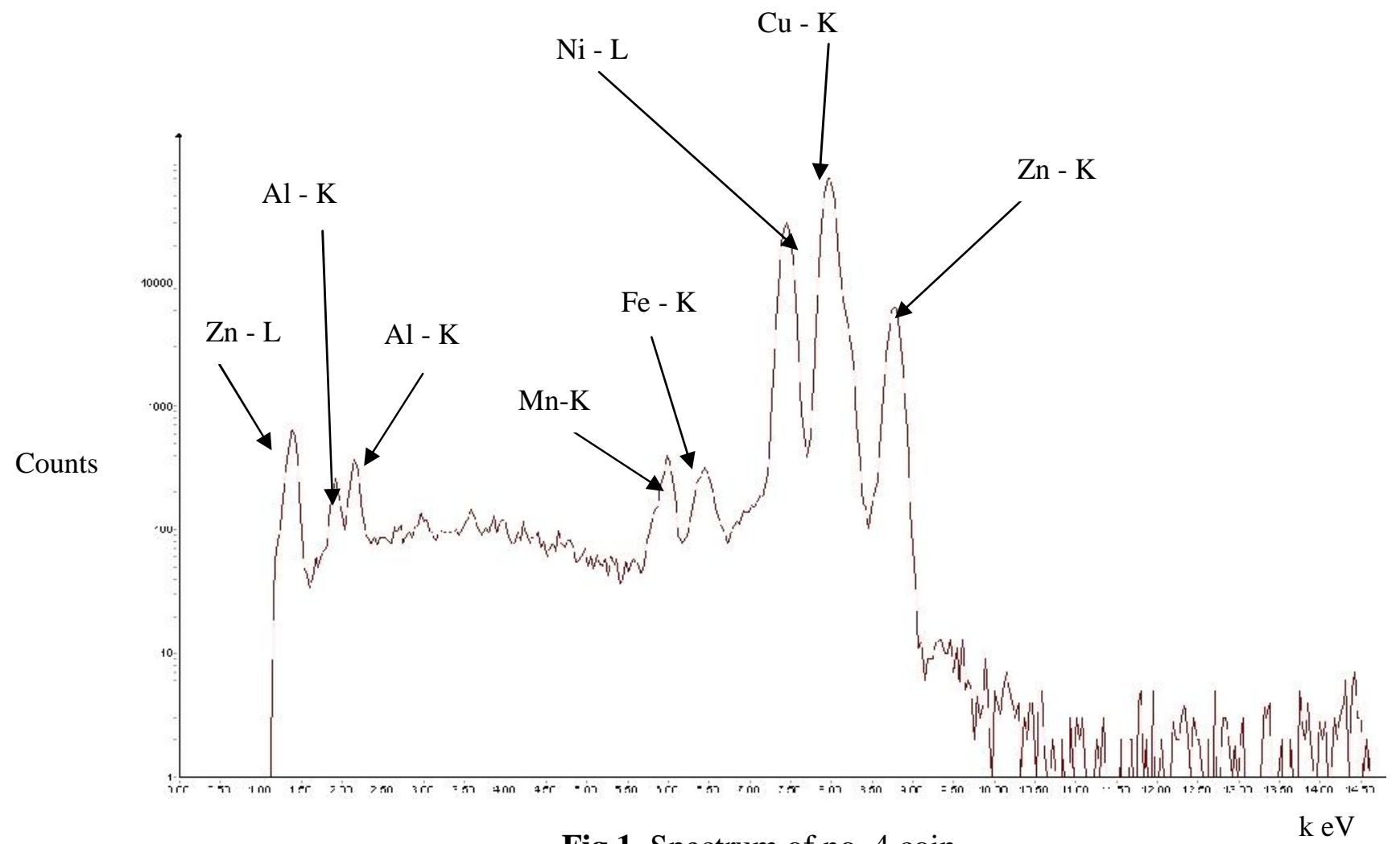

Fig.1. Spectrum of no. 4 coin

However, sample 3 was exceptionally different as it recorded the highest concentration of $\mathrm{Cu}$ (57900 $\mathrm{ng} \mathrm{cm}^{-2}$ ) while other associated major elements (Ni or $\mathrm{Zn}$ ) were not detected. Contrary, the concentrations of $\mathrm{Ni}$ in coin nos. 1, 6 and 10 were higher than other associated elements. For instance, coins labeled 1 and 2 registered Ni concentrations of $47900 \mathrm{ng} \mathrm{cm}^{-2}$ and 37510 $\mathrm{ng} \mathrm{cm}^{-2}$ respectively as the only major element. However, we observed that $\mathrm{Ni} / \mathrm{Cu}$ ratios were 
nearly the same from 0 to 0.31 which is the principal debasing components. The presence of $\mathrm{Al}, \mathrm{Si}, \mathrm{Mn}$ and $\mathrm{Fe}$ as an artifact could be related to the use of sulphide ore (chalcopyrite). The absence of arsenic and antimony in all the coins indicate modern smelting procedures and that these coins were not die-struck (Hajivaliei et al., 1999).

\subsection{Statistical analysis}

The regression plot (Fig. 2) clearly revealed a linear regression of $r^{2}=0.031$ which indicates weak or no correlation for $\mathrm{Cu}$ and $\mathrm{Ni}$. However, two points in the scatter plot were outliers due to non-detection of corresponding Ni concentration.

Pearson correlation matrices for the elements are presented in Table 4. The elements displayed positive and negative correlations. The elements displayed both negative and positive correlations. For instance, $\mathrm{Cu}$ correlated with $\mathrm{Zn}\left(r^{2}=0.24\right)$ but showed negative correlation with $\mathrm{Mn}\left(r^{2}=-0.31\right)$ and $\mathrm{Fe}\left(r^{2}=-0.18\right)$. Thus, strong correlations found between the elements could indicate a common source or chemical similarity, whilst weak correlations could imply different source origin or non-chemical similarity (Adebiyi et al., 2006). However, ore-metal correlation depends upon: a) The type of the ore, oxide or sulphide or silicate and the nature of impurities. b) The precise conditions of smelting, such as temperature, nature of fuel, flux etc., and several other factors (Biswas, 1996).

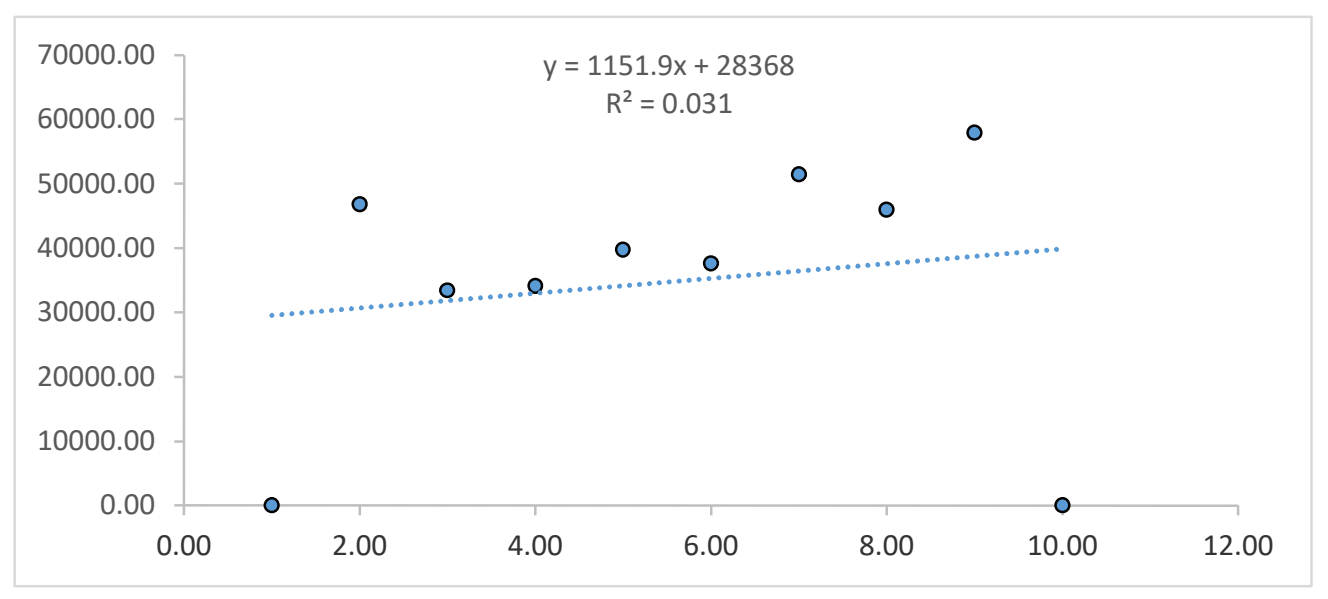

Fig.2. Regression analysis of $\mathrm{Cu}$ and $\mathrm{Ni}$ 
Table 4: Pearson correlation matrices

\begin{tabular}{l|rrrrrrr} 
& \multicolumn{1}{|c}{$\mathrm{Al}$} & \multicolumn{1}{c}{$\mathrm{Si}$} & $\mathrm{Mn}$ & $\mathrm{Fe}$ & $\mathrm{Ni}$ & $\mathrm{Cu}$ & $\mathrm{Zn}$ \\
\hline $\mathrm{Al}$ & 1.00 & & & & & & \\
$\mathrm{Si}$ & 0.70 & 1.00 & & & & & \\
$\mathrm{Mn}$ & -0.40 & -0.19 & 1.00 & & & & \\
$\mathrm{Fe}$ & 0.21 & -0.07 & -0.34 & 1.00 & & & \\
$\mathrm{Ni}$ & -0.14 & -0.41 & 0.21 & 0.49 & 1.00 & & \\
$\mathrm{Cu}$ & 0.22 & 0.42 & -0.22 & -0.56 & -.964 & 1.00 & \\
$\mathrm{Zn}$ & 0.15 & -0.16 & -0.31 & -0.18 & -0.30 & 0.24 & 1.00
\end{tabular}

\section{EXPERIMENTAL}

\subsection{Sample descriptions}

Ten coins (Fig. 3) sourced from local antiquity markets in Enugu, Nigeria were used for the study. The coins were grouped into two; colonial (coins number 7, 8, 9, 10) and post-colonial (coins number 1, 2, 3, 4, 5,6) types. The identities of the coins were one naira (1), half-kobo (2), one kobo (3), twenty-five kobo (4), five kobo (5), one naira (6), three pence (7), six pence (8), one-tenth of a penny (9) and one shilling (10).

\subsection{Sample preparation}

Although PIXE requires little or minimal sample preparations, care must be taken in handling the material to be analyzed. The samples (coins) were kept in $10 \%$ caustic soda solution for 28 days and were scrubbed with tooth brush to remove corrosion. The basic solution affects the patina only and not the core of the coins. These were then soaked inside deionized water for $3 \mathrm{hrs,}$, washed thoroughly, dried and were kept inside a desiccator prior to PIXE elemental analysis.

\subsection{PIXE set-up and analysis}

Fig. 4 displayed the schematic diagram of 1.7 MV Tandem accelerator (a facility of Centre for Energy Research and Development, Obafemi Awolowo University, Ile-Ife, Osun State Nigeria) used for the study. It has a general purpose scattering chamber designed to carry out Rutherford Back Scattering (RBS), Proton Induced Gamma Ray Emission (PIGE) and a special arrangement for Particle Induced X-ray Emission (PIXE) studies. The vacuum obtained inside the experimental chamber was of the order of $10^{-7}$ Torr.

The chamber has one view port for monitoring the beam and also equipped with a variable collimator for beam size selection of 1,2, 4, and $8 \mathrm{~mm}$. The detector signals were shaped, 
amplified and through a pulse height analysis the energy spectrum was stored and displayed in a multi-channel analyzer (Canberra-88). In this work, a beam size $(8 \mathrm{~mm})$, energy $(2.5$ $\mathrm{MeV})$ and charge $(3.0 \mu \mathrm{C})$ were used for sample irradiation. The target was positioned at $45^{\circ}$ with respect to the beam direction and the characteristic X-rays were detected by a Si-Li detector (model ESLX 30 - 50, - $500 \mathrm{~V}$ ) equipped with a $90 \mu \mathrm{m}$ Kapton filter attached to the $\mathrm{X}$-ray detector port. The filter was used as an absorber to reduce high count rate. The absorber also reduces X-ray intensities of low Z elements (Na to $\mathrm{Ca}$ ) much more as compared to high $\mathrm{Z}$ elements in order to enable the use of high beam currents for increased sensitivity of heavy metals.

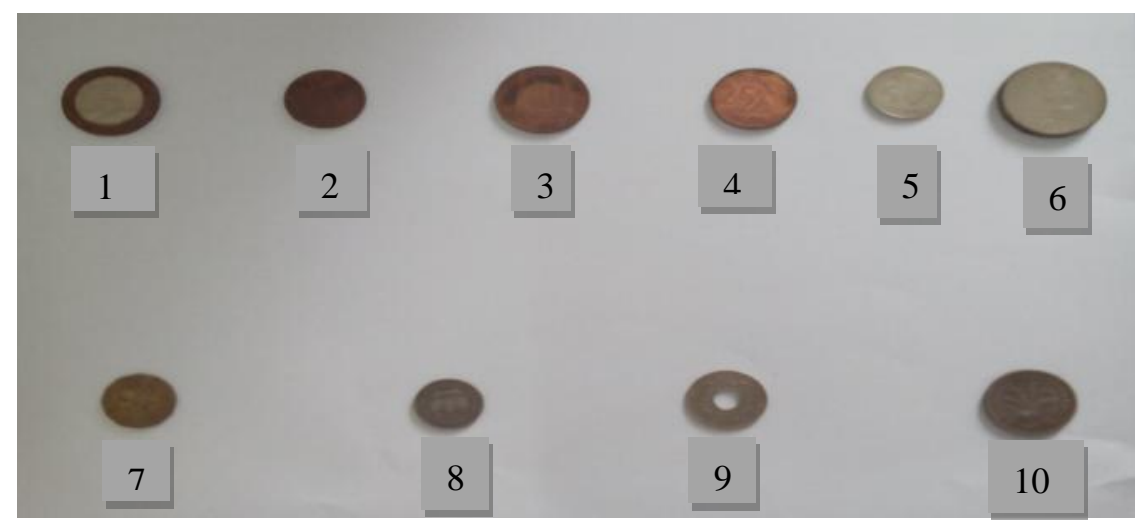

Fig.3. Pictures of the coins under study

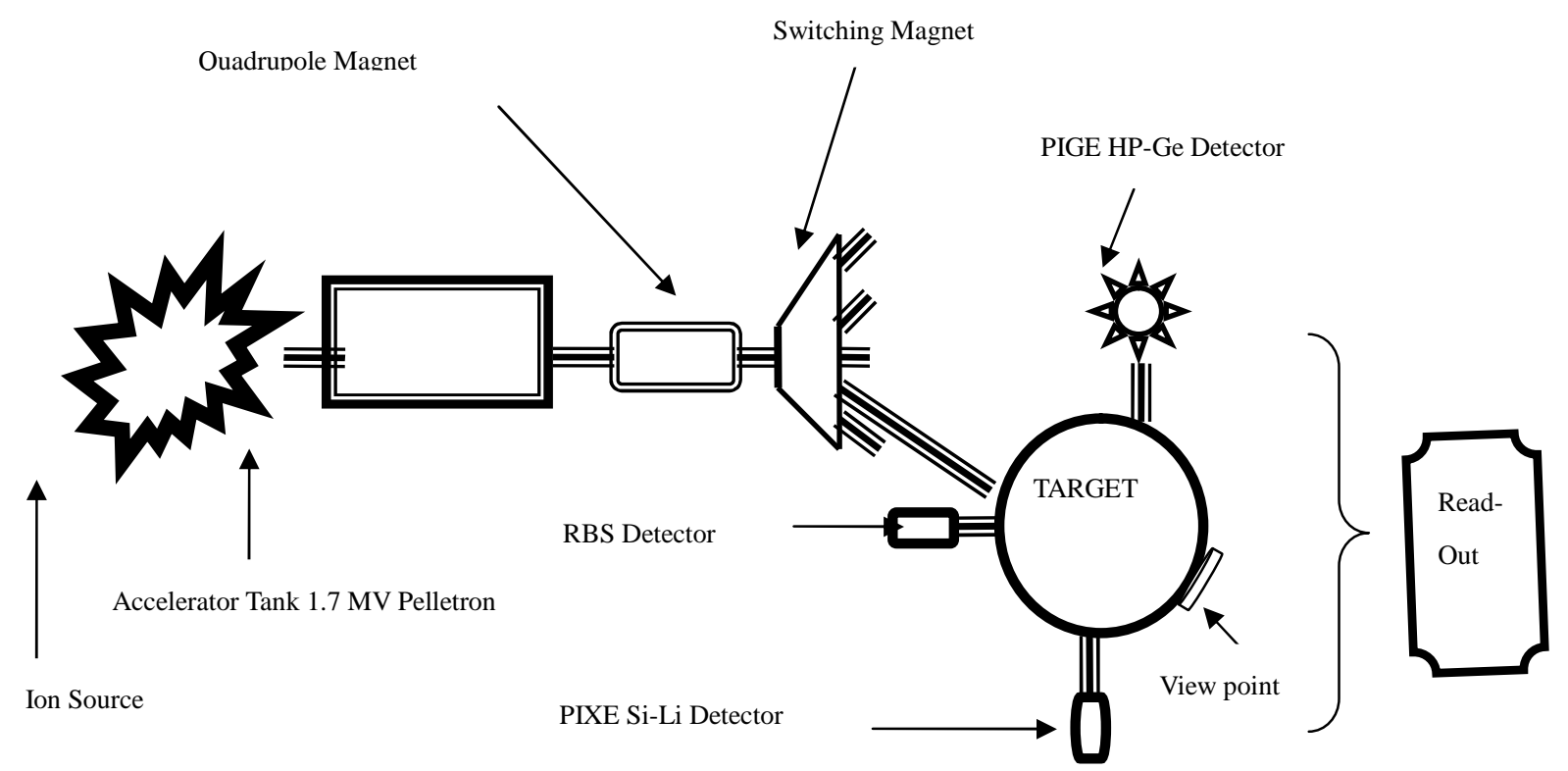

Fig.4 Schematic diagram of CERD ion beam analysis set-up

The distance between the target and the detector was $9 \mathrm{~cm}$, out of which $4 \mathrm{~cm}$ was in the air 
(outside the chamber). The beam current was integrated in the sample (for thick targets) and in a Faraday cup behind the target (for thin targets). To get accurate charge integration at the sample position, a secondary electron suppresser system applying negative $\approx 200$ volts was used. Again the beam current was kept lower than $5 \mathrm{nA}$ in order to avoid high counting rates. For reliable calibration of the analytical system (viz. X-ray yield observed by the detector per unit charge per unit mass of the element) thin Micromatter ${ }^{\circledR}$ standards were used. X-ray spectra obtained from PIXE measurements were analyzed using thick target option of computer-coded GUPIXWIN. Detailed features of the code have been explained (Cambell et al., 2010).

The choice to use GUPIX was based on several considerations; the main advantages were the good status of the databases (cross sections, fluorescence and Coster-Kronig probabilities, stopping powers, and attenuation coefficients) involved (Cambell et al., 2010). GUPIXWIN has also some useful options, such as matrix iteration, adding invisible element to the fit and analyzing spectra in batches. Calibration of the PIXE system was performed by irradiating suitable micrometer thin-film targets (Ezeh et al., 2014).

\subsection{Statistical analyses}

The elemental concentrations of the analyzed samples were subjected to statistical analysis to determine the variances, Pearson distance correlation and regression matrices of the elements. This was calculated using Statistical Package for Social Scientist (SPSS) software.

\section{CONCLUSION}

The elemental compositions of pre-colonial and post-colonial Nigerian coins were determined using proton induced x-ray emission technique (PIXE). Seven elements (Al, Si, Mn, Fe, Ni, $\mathrm{Cu}$ and $\mathrm{Zn}$ ) were detected and their concentrations established. From our results, the coins were majorly either $\mathrm{Cu}$ or $\mathrm{Ni}$ based with no significant correlation among the elements. The data obtained from this study could provide insight into some of the scientific questions of conservators and tourists on "what" material is it especially now that the coins have long been demonetized in Nigeria. 


\section{ACKNOWLEDGEMENTS}

The authors would like to acknowledge the entire Accelerator team of Centre for Energy Research and Development (CERD), Obafemi Awolowo University, Ile-Ife for beam time allocation to us.

\section{REFERENCES}

[1] Hajivaliei M, Garg M.L, Handa D.K, Govil K.L, Kakavand T, Vijayan V, Singh K.P, and Govil I.M. PIXE Analysis of ancient Indian Coins., Nuclear Instrumentation and Methods in Physics Research B., 1999, 150, 645-650.

[2] Cohen D.D, Garton D, Stelcer E, Hawas O, Wang T, Poon S, Kim J, Cheol-Choi B, Nam-Oh S, Hye-Jung S, Ko M.Y, and Uematsu M. Multi-elemental analysis and characterization of fine aerosols at several key ACE-Asia sites. Journal of Geophysical Research., 2004, 109 (D19S12) 1-16.

[3] Campbell J.L, Boyd N.I, Grassi N, Bonnick P and Maxwell J.A. The Guelph PIXE software package IV. Nuclear Instrumentation and Methods in Physics Research B., 2010, $268,(2010), 3356-3363$.

[4] Ezeh G.C, Obioh I.B, Asubiojo O.I, Chiari M, Nava S, Calzolai G, Lucarelli F, and Nuviadenu C.K. Elemental Compositions of $\mathrm{PM}_{10-2.5}$ and $\mathrm{PM}_{2.5}$ Aerosols of a Nigerian Urban City using Ion Beam Analytical Techniques. Nuclear Instrumentation and Methods in Physics Research B., 2014, 334, 28-33.

[5] Adebiyi F.M, Asubiojo O.I, and Ajayi T.R. Multi-element analysis of Nigerian bitumen by TXRF spectrometry and physical constants characterization of its hydrocarbon component. Fuel., 2006, 85, 396-400.

[6] Biswas A.K. Minerals and Metals in Ancient India. Archealogical Evidence, Volume 1, Printworld, India 1996.

\section{How to cite this article:}

Ezeh G.C, Obiajunwa E.I. Multi-elemental analysis of colonial and post-colonial Nigerian coins by proton induced x-ray emission (PIXE) spectrometry. J. Fundam. Appl. Sci., 2017, 9(1), 499-508. 